\title{
PENERAPAN NEAR FIELD COMMUNICATION PADA SISTEM PEMBAYARAN OTOMATIS TRANSPORTASI BUS BERBASIS INTERNET OF THINGS
}

\author{
Yuri Nur Kholipa ${ }^{1}$, Dahlia Widyaestoeti, S.Kom, M.Kom ${ }^{2 *}$, Andik Eko Kristus Pramuko, S.Si., M.T ${ }^{3^{*} \text {, }}$ \\ Program Studi Teknik Informatika, Fakultas Teknik \& Sains1,2,3 \\ Universitas Ibn Khaldun Bogor \\ Jl.KH Sholeh Iskandar Km 2 Kota Bogor \\ yuri.nurkholipa@gmail.com¹, dahlia@uika-bogor.ac.id ${ }^{2}$, andiekokp@gmail.com ${ }^{3}$
}

\begin{abstract}
Abstrak
Sistem pembayaran berawal dari manual seperti transaksi tunai hingga meningkat menjadi sistem pembayaran digital. Sistem pembayaran otomatis dengan menerapkan teknologi NFC dirancang pada penelitian ini. Analisis yang dilakukan dengan analisis proses bisnis dan analisis sistem. Perancangan sistem yang dilakukan dengan membuat perancangan UML (Unified Modelling Language) menggunakan metode waterfall, perancangan database, dan perancangan User Interface. Hasil dari penelitian ini adalah Web yang dapat membaca data penumpang dari menerapkan NFC, memotong saldo penumpang dan pengiriman notifikasi saldo pada aplikasi Telegram secara otomatis dengan bantuan IoT yang berfungsi sebagai konektifitas. Penilaian dari pengujian Black Box pada sistem dengan derajat nilai modul pengguna yaitu 0.91 .
\end{abstract}

Kata kunci : : Pembayaran, NFC, IoT, Telegram.

\section{Abstract}

The payment system goes from a manual to a cash transaction to a digital payment system. Automatic payment systems with NFC technology designed on this research. Analysis of business processes and systems analysis. Unified modelling language is designed using the waterfall method, database design, and user interface. The result of this study is $a$ web that can read passenger data from applying NFC, cut off the passenger balance and the automatically transfer of notification on a telegram application with the help of a iot that serves as a connectivity. The assessment of the black box testing on the system with the user module value degree is 0.91 .

Keywords: Payment, NFC, IoT, Telegram.

\section{Pendahuluan}

Sistem pembayaran adalah sebuah penunjang dalam kestabilan pada sistem keuangan yang telah berkembang. Berawal dari sebuah sistem pembayaran manual seperti transaksi tunai hingga meningkat menjadi sistem pembayaran digital atau electronic payment (E-payment).[1] Peningkatan tersebut menjadi sebuah tolak ukur bagi masyarakat untuk menerapkannya dalam bertransaksi, terutama dalam pembayaran transportasi. Namun saat ini penerapan pembayaran transportasi masih menggunakan sistem pembayaran tunai, secara spesifik diketahui pembayaran tersebut tidaklah efektif dan efisien. Proses transaksi memerlukan waktu yang sangat lama dan pengelola kesulitan dalam menyediakan uang kembalian. [2]

Dari segi transportasi bus memiliki kekurangan yaitu sistem pembayaran yang masih menerapkan transaksi dengan cara penumpang harus membeli tiket secara manual kemudian penumpang akan mendapat berupa secarik kertas sebagai bukti bahwa transaksi berhasil diproses. sistematika tersebut tidak memudahkan bertrasaksi dan membutuhkan waktu yang sangat panjang. Sistem pembayaran kembangakan kembali dengan adanya kartu elektronik alias e-ticketing. Tetapi mekanisme tersebut belum berjalan optimal, karena reader yang berfungsi untuk tapcash masih belum terpasang secara otomatis pada halte, sehingga tim pekerja bus harus membawa reader sepanjang perjalanan.

Sebuah ide muncul saat adanya satu perangkat yang dapat melakukan transaksi dengan jarak pendek dan kecepatannya tidak membutuhkan waktu yang lama yaitu dinamai Near Field Communication atau NFC. NFC adalah perangkat standard yang memungkinkan smartphone dan perangkat pintar bisa berkomunikasi ketika didekatkan. [3] NFC juga merupakan gabungan antara smartcard dan smartcard reader yang 
ditanami didalam satu perangkat, umumnya perangkat tersebut merupakan perangkat mobile seperti telepon genggam atau ponsel. [4]

Dari uraian yang telah diberikan, penelitian ini menerapkan NFC dengan membuat sistem pembayaran trasnportasi bus dengan membaca data dari NFC reader yang terpasang pada pintu bus, kemudian melakukan perhitungan agar saldo dapat terpotong dari NFC tag yang dipasang pada smartphone dan tersimpan otomatis di dalam database yang memiliki pengolahan data saldo kemudian melakukan proses selanjutnya yaitu database akan mengirimkan notifikasi sisa saldo pada smartphone melalui aplikasi Telegram penumpang bus. Terjadinya pertukaran informasi tersebut adanya dukungan dengan menggunakan basis Internet of Things atau IoT. IoT adalah jaringan internet yang dapat memindahkan informasi dari perangkat seperti sensor secara real time dan terus menerus. [5]

\section{KAJIAN LITERATUR}

\section{Pembayaran dengan NFC}

Sistem pembayaran merupakan sistem yang Perkembangannya melalui transfer transaksi elektronik dan kartu kredit yang digemari banyak orang. orang-orang mulai menggunakan metode pembayaran itu yang memberikan dampak transaksi via internet. Karenanya, keberadaan sistem pembayaran non tunai memudahkan banyak orang dan turut melahirkan berbagai macam jenis metode pembayaran non tunai yang hadir di Indonesia. [6] Metode pembayaran non tunai atau sering disebut pembayaran digital ini memiliki jenis pembayaran berupa pembayaran pengisian saldo pada perangkat telepon, komunikasi seluler jarak dekat (Near Field Communication/ NFC ), dan sebagainya. Namun, aplikasi pembayaran seluler bebasis NFC yang paling banyak dipakai dan kita temukan seperti google wallet dan lain sebagainya. [7]

\section{Near Field Communication (NFC)}

Near Field Communication (NFC) merupakan sebuah teknologi konektivitas nirkabel jarak pendek yang merupakan bentuk pengembangan dari teknologi Radio Frequency Identification Device (RFID). NFC berfrekuensi pada 13,65 MHz dengan kecepatan transmisi pengiriman data mencapai 424 $\mathrm{kbi} / \mathrm{s}$ dan jarak transmisinya hingga $4-10 \mathrm{~cm}$. [8] Dua perangkat yang kompatibel dengan NFC berkomunikasi (bertukar data) dalam jarak beberapa sentimeter. Jangkauan transmisi yang begitu pendek membuat penyadap sulit dilakukan, dan dengan demikian membantu mencapai keamanan komunikasi lebih baik. [9] Sebenarnya NFC sangat mirip dengan Bluetooth, yaitu sama-sama dapat bertukar data pada sebuah ponsel yang perangkat lainnya. tetapi ada sejumlah perbedaan yang jelas. Salah satu perbedaan utama antara NFC dan Bluetooth adalah rentang TS, karena Bluetooth dapat berjalan dari 10 hingga 100 meter, tetapi NFC biasanya lebih baik ketika dua perangkat berjarak tidak lebih dari $20 \mathrm{~cm}$.

\section{Internet of Things (IoT)}

IoT adalah sebuah perkembangan teknologi yang dapat menyelesaikan permasalahan yang dapat melalui adanya beberapa teknologi yang berfungsi dalam memenuhi kebutuhan infomasi bagi masyarakat. Internet of Things sebuah konsep yang muncul ketika semua alat dan layanan terhubung satu dengan yang lain dengan mengumpulkan, bertukar dan memproses data secara dinamis. [10] IoT dapat dipahami dari gabungan 2 kata yakni "Internet" dan "Things". Dimana "Internet" sendiri dapat didefinisikan sebagai sebuah jaringan komputer yang menggunakan protokol internet (TCP/IP) digunakan dalam berkomunikasi dan berbagi informasi dalam sebuah lingkup tertentu, sedangkan "Things" adalah sebagai objek-objek dari dunia fisik yang diambil melalui sensor-sensor yang dikirim melalui internet dan penyajian diharapkan dapat lebuh mudah dimengerti oleh stack holder. [11]

\section{Telegram}

Telegram adalah aplikasi pesan dengan fokus pada kecepatan dan keamanan, sangat cepat, sederhana, dan gratis. Telegram dapat digunakan di semua perangkat secara bersamaan. pesan dapat disinkronkan dengan mulus di sejumlah ponsel, tablet, atau komputer. Telegram memiliki kelebihan yaitu adanya landasan untuk mengunakan Application Programming Interface(API) untuk masyarakat luas. Salah satu API yang disediakan adalah fitur bot. Bot Telegram adalah bot yang saat ini mulai populer dipergunakan. [12] Telegram mulai banyak digunakan masyarakat untuk melakukan percakapan sehari-hari walau keberadaan Telegram belum sepopuler seperti Whatsapp, BBM, maupun Line tetapi bisa jadi suatu 
saat akan menjadi suatu messenger yang potensial digunakan lebih banyak.

\section{Analisis dan Perancangan}

\section{Urutan Pelaksanaan Penelitian}

Pelaksanaan penelitian ini dimulai dengan Tahap Analisis, Tahap Desain, Tahap Implementasi, hingga pada tahapan terakhir pada penelitian ini adalah tahapan pengujian secara menyeluruh. Semua proses tahapan diatas terjadi setelah urutan pelaksanaan penelitian telah dikonsepkan. Maka dapat dilihat pada Gambar 1.

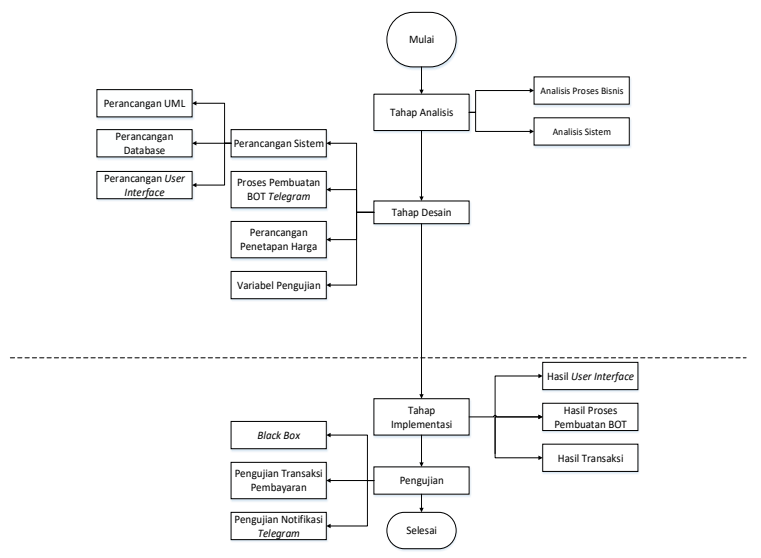

Gambar 1. Diagram Alir Urutan Pelaksanan Penelitian

Pada penelitian ini Metode perancangan yang diterapkan adalah dengan menggunakan model waterfall. Model ini biasa disebut siklus hidup klasik, karena menyarankan pendekatan sistematis, untuk pengembangan perangkat lunak yang dimulai dengan spesifikasi kebutuhan pengguna dan berkembang melalui perencanaan, pemodelan, konstruksi, dan penerapan, yang kemudian terus berkembang pada dukungan berkelanjutan dari perangkat lunak yang telah selesai.

\section{Analisis proses bisnis sistem yang diusulkan}

Analisis Proses bisnis adalah sebuah rantai aktivitas berulang yang berhubungan secara logis untuk mengolah sebuah obyek (fisik atau mental) dengan tujuan untuk hasil yang terukur dan telah ditentukan. Pada penelitian ini terdapat proses bisnis yaitu suatu sistem yang diusulkan. Sistem pembayaran yang diusulkan saat ini terdiri dari enam alur yang dapat digambarkan pada Gambar 2.

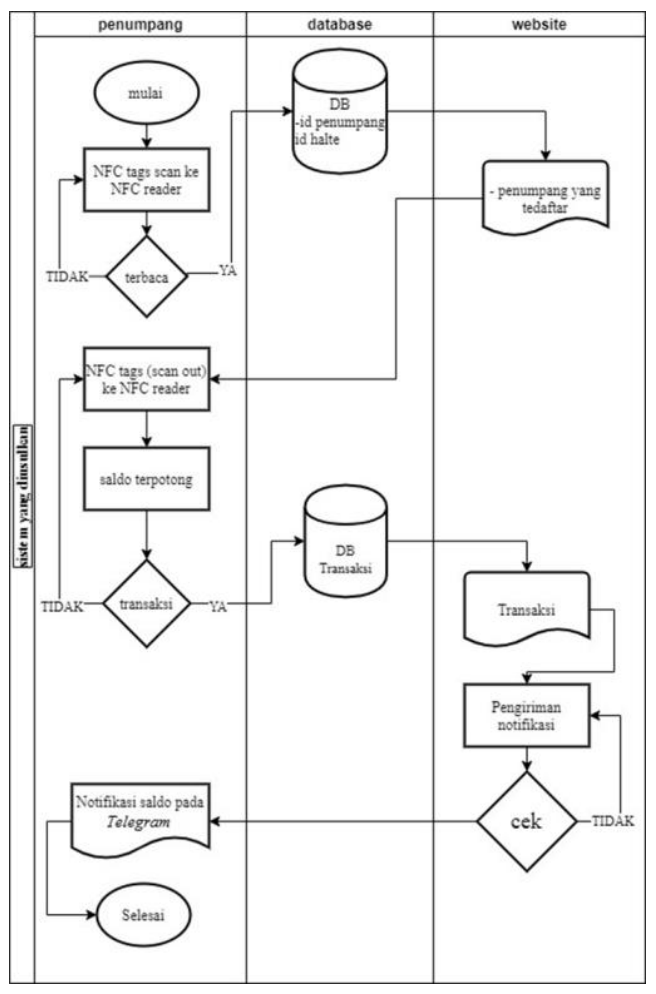

Gambar 2. Proses Bisnis sistem yang diusulkan

\section{Analisis Sistem}

Pada proses ini dilakukan sebuah teknik pemecahan masalah dengan cara menguraikan sistem yang dibuat ke dalam komponen-komponen agar dapat mengetahui bagaimana komponenkomponen tersebut bekerja dan saling berinteraksi satu sama lain untuk mencapai tujuan pada penelitian ini.

\section{Perancangan Sistem}

perancangan sistem yang dilakukan terkait dengan perancangan UML (Unified Modelling Language) yang nantinya ditampilkan pada web sederhana yang telah ditentukan sesuai dengan kriteria desain. Pada perancangan UML akan melakukan pemodelan (modelling) yang melakukan sebuah tahapan yang merancang perangkat lunak sebelum melakukan tahap pembuatan program (coding). Sehingga akan diketahui semua entitas luar, input dan output yang terlibat dalam sistem. Aktivitas perancangan sistem dapat digambarkan pada use case diagram. diagram dapat dilihat pada Gambar 3. 


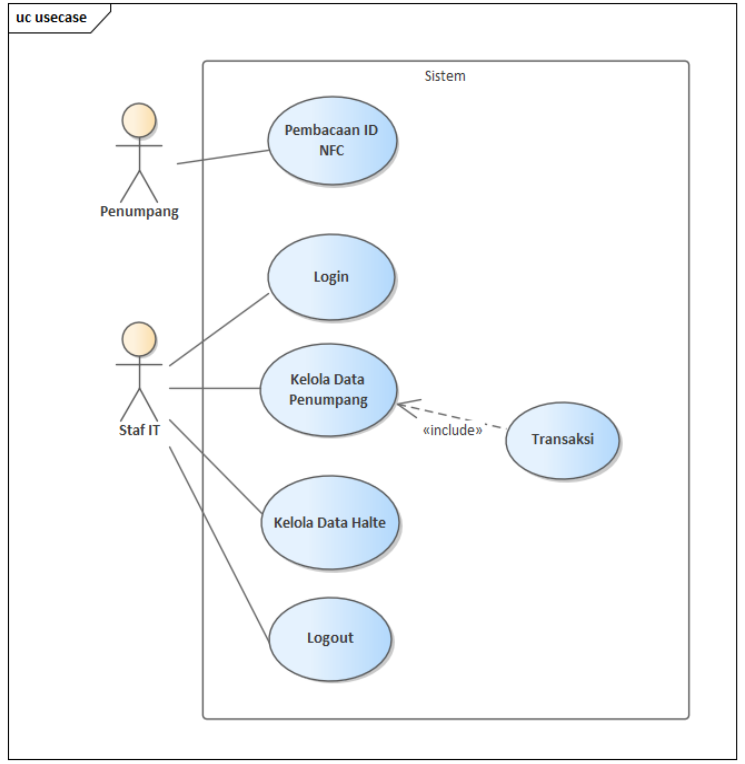

Gambar 3. Use Case Diagram

\section{Perancangan Database}

Desain database pada penelitian ini digunakan untuk merancang masukan data yang bertujuan membentuk sebuah sistem basis data yang saling terhubung dan berelasi antara tabel satu dengan yang lainnya. Selain itu desain database ini digunakan juga untuk menentukan tipe datanya serta panjang karakter masing-masing field. Desain database dijelaskan pada relasi antar tabel. Pada penelitian ini dapat dilihat pada Gambar 4.

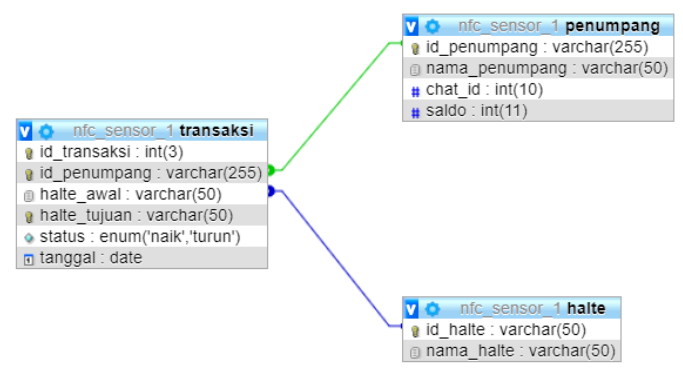

Gambar 4. Relasi Antar Tabel

\section{Perancangan Interface}

Perancangan interface adalah rancangan dasar aplikasi yang dibuat. Desain antarmuka ini merupakan menu- menu pada aplikasi web yang sudah dirancang sebelumnya. Pada menu web ini terdapat 6 (enam) submenu.

\section{Proses Pembuatan Bot Telegram}

Pada penelitian ini tahapan ini melakukan proses pembuatan bot telegram dengan memanfaatkan "BotFather" yang tersedia pada telegram untuk menciptakan bot sendiri yang dijadikan sebagai akun penerima informasi. Ketika membuka akun "BotFather", tulis "/start" untuk memulai pecakapan, setelah itu "BotFather" mengirim manage Telegram bots yang berisi tentang kode-kode untuk memanggil perintah yang ingin kita inginkan. Proses tersebut dapat dilihat pada Gambar 5. Kemudian "BotFather" mengirimkan token akun bot yang telah dibuat agar dapat diakses untuk digunakan dalam pembuatan notifkasi didalam sistem. Token akan didapatkan seperti pada Gambar 6.

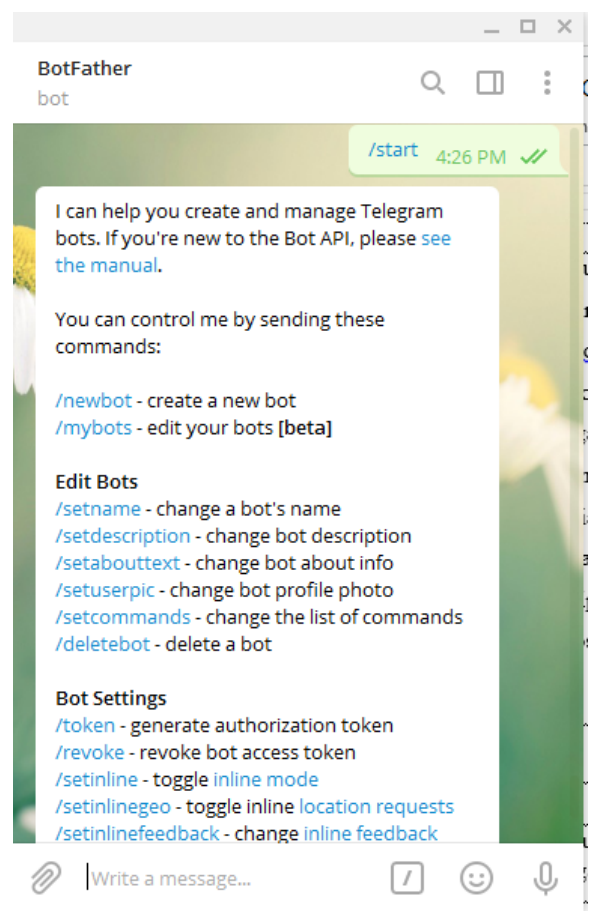

Gambar 5. "BotFather" 


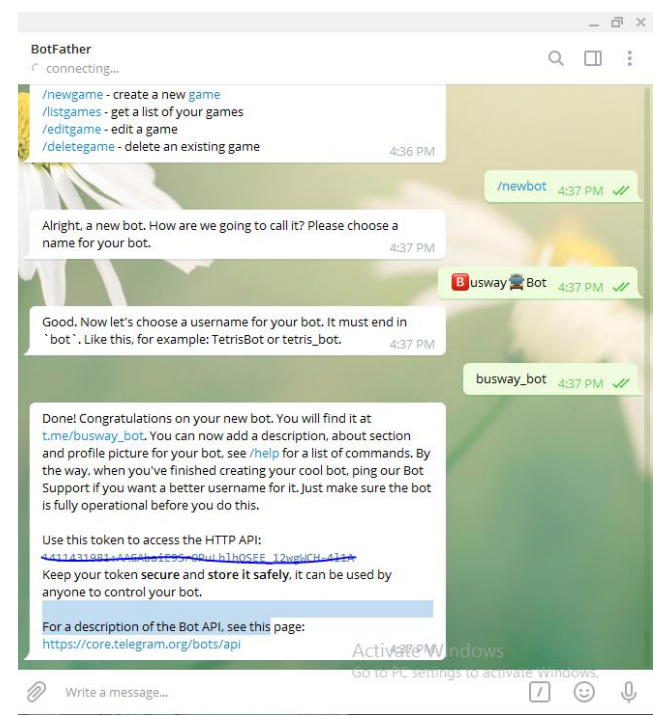

Gambar 6. /NewBot

\section{Hasil dan Pembahasan}

\section{Implementasi Interface}

1. Login

Tampilan halaman login dari web dapat dilihat pada Gambar 7.

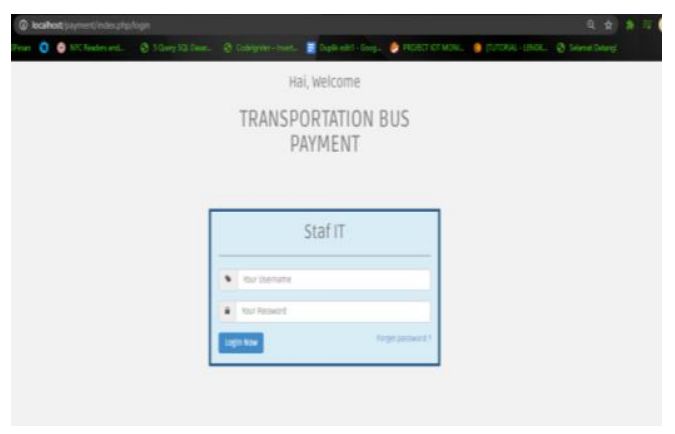

Gambar 7. Login

2. Beranda

Tampilan halaman beranda dari web dapat dilihat pada Gambar 8.

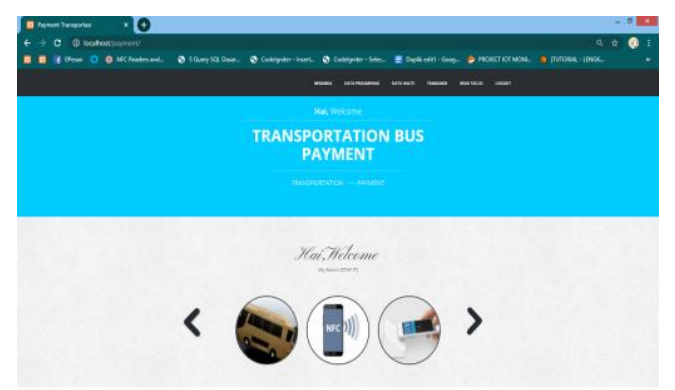

Gambar 8. Beranda

3. Data Penumpang

Tampilan halaman data penumpang pada web dapat dilihat pada Gambar 9.

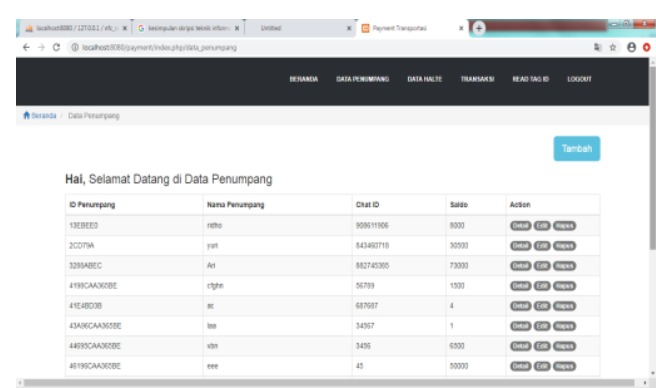

Gambar 9. Data Penumpang

4. Data Halte

Tampilan halaman data halte pada web dapat dilihat pada Gambar 10.
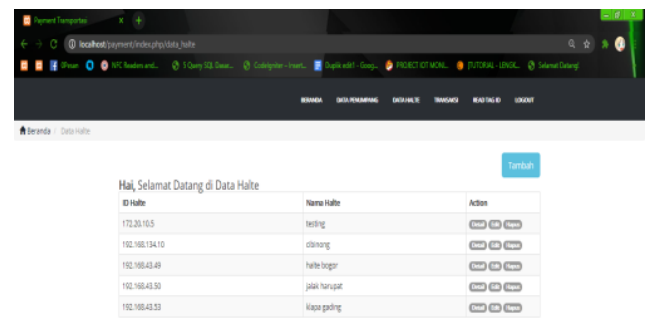

Gambar 10. Data Halte 
5. Transaksi

- Tampilan halaman transaksi pada web dapat dilihat pada Gambar 11.

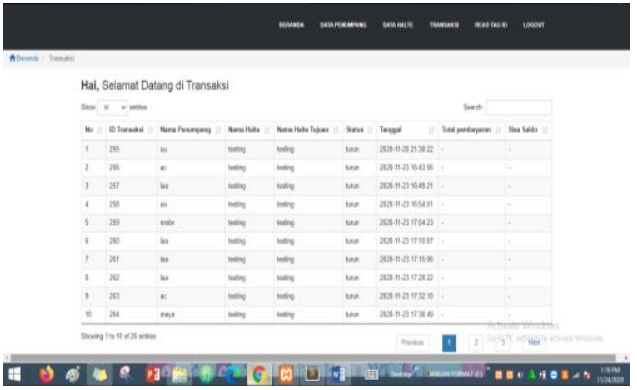

Gambar 11. Transaksi

6. Read Id

Tampilan halaman Read Tag Id pada web dapat dilihat pada Gambar 12.

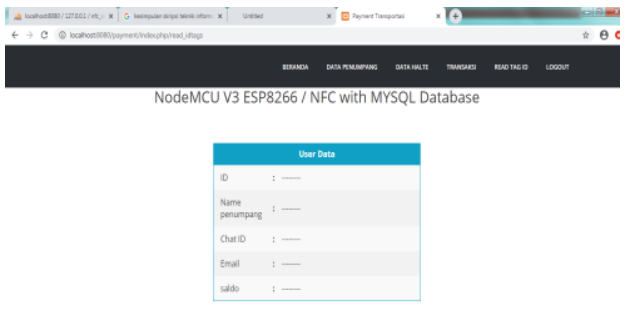

Gambar 12. Read Id

7. Logout

Tampilan halaman logout pada web dapat dilihat pada Gambar 13.

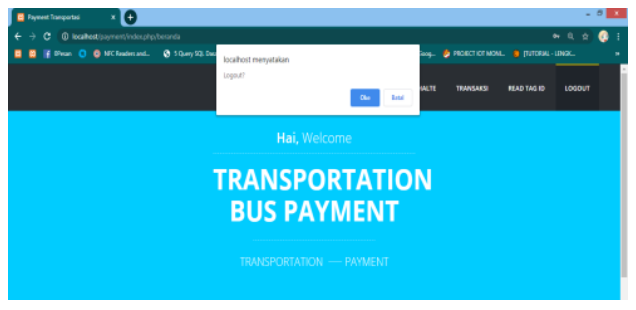

Gambar 13. Logout

\section{Pengujian BlackBox}

Pengujian ini dilakukan pada sistem ini adalah pengujian menggunakan Black Box. Pengujian Black Box adalah suatu pendekatan untuk menguji apakah fungsi yang ada disetiap program dapat berjalan dengan benar tanpa memperdulikan stuktur kendali di dalam program. Pengujian tersebut dapat diartikan sebagai pengujian fungsional, karena dapat menguji apakah program berjalan sesuai spesifikasi kebutuhan (requirement). Perencanaan pengujian Black Box yang akan di uji pada Tabel 1.

\begin{tabular}{ll}
\hline \hline Kelas Uji & Butir Uji \\
\hline Log in & Pengecekan user \\
Halaman Admin / & Beranda \\
Staf IT & Kelola Data Penumpang \\
& Kelola Data Halte \\
& Transaksi \\
& Read Id NFC \\
\end{tabular}

Table 1. Pengujian

Pada pengujian Black Box dilakukan proses penilaian dengan melihat skala yang didasarkan pada nilai bobot peran modul dan nilai pengguna berdasarkan nilai bobot. Proses kedua ini dapat dijelaskan sebagai berikut:

1. Nilai bobot peran modul, jika nilai bobot bernilai 1 maka peran modul bersifat tidak kritis, sedangkan nilai bobot bernilai 4 maka peran modul bersifat kritis. Peran modul yang bersifat tidak kritis adalah modul yang tidak berpengaruh terhadap modul lain. Modul tersebut juga berperan dalam membantu modul-modul lain yang bersifat kritis. Sedangkan peran modul yang bersifat kritis adalah modul yang berperan terhadap modul-modul lain, dan modul ini harus segera diuji dan kemudian terjadi error maka modul ini menghasilkan dan mengganggu modul lain.

2. Nilai pengguna berdasarkan nilai bobot, pertama pemenuhan kebutuhan pengguna dianggap baik jika derajat nilai modul pengguna $\geq 0.80$. kedua pemenuhan kebutuhan pengguna dianggap buruk jika derajat nilai modul pengguna $<0.80$.

Hasil dari pengujian BlackBox dengan berdasarkan nilai pengguna, derajat nilai pengguna adalah 0.91 dengan pemenuhan kebutuhan pengguna yaitu "Baik". 


\section{Pengujian Transaksi dan Notifikasi Telegram}

Pengujian ini bertujuan untuk melihat bagaimana pengurangan saldo pada setiap kali transaksi dilakukan dan Pengujian notifikasi ini bertujuan untuk melihat bagaimana web dapat mengirim informasi setiap transaksi dilakukan. Pengujian ini dilakukan ketika penumpang sudah bertransaksi, maka setelah transaksi berhasil web mengirim notifikasi pada telegram. Pengujian transaksi dapat dilihat pada Gambar 14. Pengujian notifikasi telegram dapat dilihat pada Gambar 15.

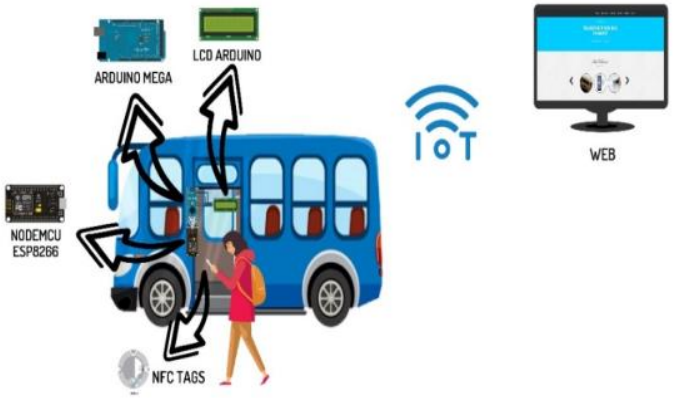

Gambar 14. Pengujian Transaksi
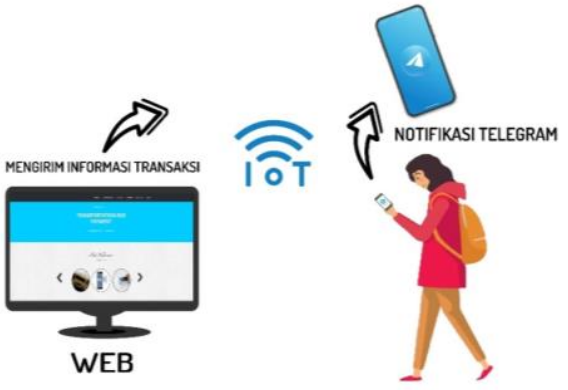

Gambar 15. Pengujian Notifikasi

Hasil dari pengujian dapat melihat apakah sistem dapat mengirimkan notifikasi berupa informasi saldo penumpang yang telah melakukan transaksi pembayaran dapat berhasil dikirimkan melalui web yang telah memiliki masing-masing chat id setiap akun telegram penumpang. Maka hasil tersebut dapat dilihat pada Gambar 16.

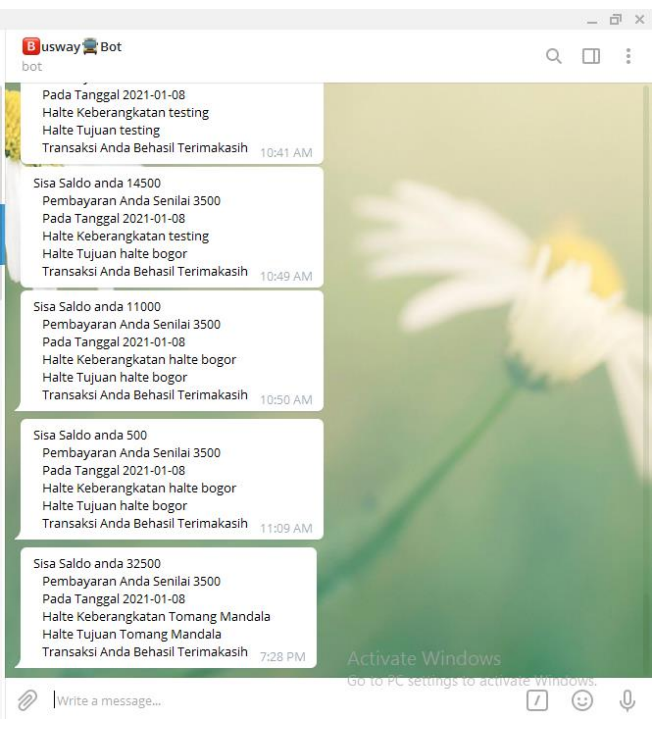

Gambar 16. Hasil Pengujian

\section{KESIMPULAN DAN SARAN}

\section{Kesimpulan}

Kesimpulan hasil penelitian ini merupakan rangkuman/intisari dari rangkaian pembahasan pada bab- bab sebelumnya dan rangkaian perancangan yang telah dikerjakan, maka dapat ditarik kesimpulan pada beberapa hal sebagai berikut:

1. Penerapan NFC untuk membaca data penumpang transportasi bus telah berhasil terbaca dan tesimpan pada web.

2. Pemotongan saldo telah berhasil dibangun sesuai dengan transaksi yang dilakukan kemudian telah tesimpan pada web. Dan pengiriman notifikasi saldo berhasil dikirim pada aplikasi Telegram secara otomatis.

\section{Saran}

Berdasarkan kesimpulan diatas, maka peneliti menyampaikan saran kepada berbagai pihak sebagai bahan masukan untuk pertimbangan dan perbaikan sebagai berikut:

1. Untuk peneliti selanjutnya agar dapat meneliti mengenai penerapan NFC dengan menggunkan aplikasi pada Smartphone untuk pembayaran Transportasi Bus. 
2. web pembayaran Transportasi bus yang dibuat peneliti belum memiliki fitur dan menu yang lengkap, maka diharapkan untuk peneliti selanjutnya dapat menambahkan fitur dan menu contohnya seperti penambahan menu form pendaftaran penumpang pada web staf IT dan penambahan fitur untuk penumpang atau user.

\section{REFERENSI}

[1] J. Tarantang, A. Awwaliyah, M. Astuti, and M. Munawaroh, "Perkembangan Sistem Pembayaran Digital Pada Era Revolusi Industri 4.0 Di Indonesia," J. Al-Qardh, vol. 4, no. 1, pp. 60-75, 2019, doi: 10.23971/jaq.v4i1.1442.

[2] T. Ihsan and R. E. Putri, "Sistem Pembayaran Tiket Bus Rapid Transit ( Brt ) Menggunakan Near Field Communication ( Nfc )," no. November, pp. 1-8, 2016.

[3] B. W. Harimurti, W. Kurniawan, and H. Nurwarsito, "Sistem Pengelolaan Parkir Dengan NFC," J. Pengemb. Teknol. Inf. dan Ilmu Komput. Univ. Brawijaya, vol. 2, no. 6, pp. 2038-2045, 2018.

[4] N. Rismawati, "Sistem Absensi Dosen Menggunakan Near Field Communication ( Nfc ) Technology," Fakt. Exacta, vol. 9, no. 2, pp. 135-142, 2016.

[5] N. A. Hidayatullah and D. E. Juliando, "Desain dan Aplikasi Internet of Thing (IoT) untuk Smart Grid Power Sistem," VOLT J. Ilm. Pendidik. Tek. Elektro, vol. 2, no. $1, \quad$ p. $35, \quad 2017$, doi: 10.30870/volt.v2i1.1347.

[6] S. S. D. Sari, S.E., M.M. , Vivi Nila; Anggraini, Revolusi Uang Digital Era. 5.0 Transaksi Digital. CV. Insan Cendekia Mandiri, 2020.

[7] T. Rumondang, Astri; Sudirman, Acai; Effendy, Faried; Simarmata, Janner; Agustin, Fintech: Inovasi Sistem Keuangan di Era Digital. Yayasan kita Menulis, 2019.

[8] M. Rifqi and N. Wardhani, "Aplikasi Peran Dan Kegunaan Teknologi Near Field Communication (Nfc) Terhadap Kegiatan Proses Belajar Mengajar Di Perguruan Tinggi," J. Ilmu Tek. dan Komput., vol. 1, no. 1, pp. 20-26, 2017.

[9] M. Ahson, Syed A; Ilyas, Near Field Communications Handbook. London, New York: CRC Press, 2016.

[10] M. R. Hidayat, C. Christiono, and B. S. Sapudin, "PERANCANGAN SISTEM 
KEAMANAN RUMAH BERBASIS IOT

DENGAN NodeMCU ESP8266

MENGGUNAKAN SENSOR PIR HC-

SR501 DAN SENSOR SMOKE

DETECTOR," Kilat, vol. 7, no. 2, pp. 139148, 2018, doi: 10.33322/kilat.v7i2.357.

[11] S. Sukaridhoto, ST. Ph.D, "Politeknik Elektronika Negri Surabaya," in Bermain dengan Internet of Things \& BigData, Surabaya: PENS, 2016, pp. 9-10.

[12] A. Cokrojoyo, J. Andjarwirawan, and A. Noertjahyana, "Pembuatan Bot Telegram Untuk Mengambil Informasi dan Jadwal Film Menggunakan PHP," J. Infra, vol. 5, no. 1, pp. 224-227, Program Studi Teknik Informatika Fakultas, 2017, [Online]. Available:

http://studentjournal.petra.ac.id/index.php/te knik-informatika/article/view/5163. 